\title{
Willingness to Pay for Attributes of Biodegradable Plastic Mulches in the Agricultural Sector
}

\author{
Kuan-Ju Chen ${ }^{1}$, Suzette P. Galinato ${ }^{2}$, Thomas L. Marsh ${ }^{1,3}$, \\ Peter R. Tozer ${ }^{4}$, and Hayley H. Chouinard ${ }^{5}$
}

ADDITIONAL INDEX WORDs. choice experiment, green agriculture technology, plastic residue, soil health, sustainability

Summary. To mitigate the environmental harm associated with the disposal of polyethylene (PE) (plastic) mulches after use-incineration, dumping at landfills, tilling into the soil, and onsite stockpiling-biodegradable plastic mulches (BDMs) are proposed as an environmentally friendly alternative. These mulches are designed to degrade in the field, thereby reducing negative impacts. We conducted discrete choice experiments to evaluate willingness to pay (WTP) for BDM attributes using data collected from a survey of stakeholders in the agricultural sector (e.g., farmers, crop advisors, educators, and others) in the Pacific Northwest region of the United States. Results obtained using a mixed logit model show that respondents assign the greatest value to BDM attributes that provide a price premium opportunity for the product grown, improve soil health, or reduce field-borne residue, thereby enhancing sustainability. We found heterogeneity in preferences for the attributes of plastic residue and soil health: the cost of BDMs is more important to nonfarmers and noncrop advisors, whereas soil health is more of a concern for crop advisors. In addition, respondents who are less risk averse and less sensitive to cost are more willing to adopt BDMs. Results from this study have implications regarding the best ways to introduce and support sustainable practices as a part of green technology in the agricultural sector, particularly for new BDM products.

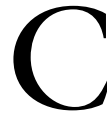

ontamination caused by plastic pollution on land and in rivers, canals, and oceans has

Received for publication 30 Sept. 2019. Accepted for publication 15 Apr. 2020.

Published online 14 May 2020.

${ }^{1}$ College of Natural and Applied Sciences, University of Guam, 303 University Dive, UOG Station, Mangilao, GU 96913

${ }^{2}$ School of Economic Sciences, IMPACT Center, Washington State University, P.O. Box 646210, Hulbert Hall, Pullman, WA 99164

${ }^{3}$ Paul G. Allen School for Global Animal Health Allen Center, Washington State University, P.O. Box 647090, 1155 College Avenue, Pullman, WA 99164

${ }^{4}$ School of Agriculture and Environment, Massey University, Private Bag 11 222, Palmerston North 4442 , New Zealand

${ }^{5}$ Department of Agricultural and Resource Economics, Colorado State University, B317 Clark Building, Campus Delivery 1172, Fort Collins, CO 80523

This study was funded by the project "Performance and Adoptability of Biodegradable Plastic Mulch for Sustainable Specialty Crop Production," which was supported by the U.S. Department of Agriculture National Institute of Food and Agriculture through its Specialty Crop Research Initiative (award no. 2014-51181-22382). Additional assistance with survey distribution was provided by Chris Benedict, Agriculture Extension Agent, Washington State University.

K.-J.C. is the corresponding author. E-mail: chenkj@ triton.uog.edu.

This is an open access article distributed under the CC BY-NC-ND license (https://creativecommons.org/ licenses/by-nc-nd $/ 4.0 /$ )

https://doi.org/10.21273/HORTTECH04518-20 become a major global environmental issue. Plastic represents an environmental hazard because it is made from fossil fuel resources and does not degrade easily (Özkan et al., 2015). Single-use plastic waste increases by $\approx 50 \%$ worldwide each year, and just $5 \%$ of it is recoverable through various types of recycling (D'Alessandro, 2014). Agricultural plastic pollution is a pervasive problem to which the plastic mulches used in the production of many specialty crops (e.g., vegetables and fruits) contribute (Brodhagen et al., 2015; Ghimire et al., 2018; Vox et al., 2016).

Polyethylene (PE) plastic mulch films are the most common type of mulch used among growers of specialty crops because of their widespread availability, soil temperature modifications, improved weed management, ease of mechanical application, labor cost savings, high durability, and ability to increase crop yields (Kyrikou and
Briassoulis, 2007; Steinmetz et al., 2016). PE mulch made from nonrenewable, petroleum-based feedstock is typically used for only one growing season before disposal (Goldberger et al., 2015). The use of plastic mulches in agriculture has increased significantly worldwide during the past few years (Kasirajan and Ngouajio, 2012). The agricultural sector uses more than 6 million tonnes of plastic materials annually (Scarascia-Mugnozza et al., 2011).

Increased use of plastic mulches has led to serious waste issues and irreversible soil pollution from nonbiodegradable and nonrecoverable PE fragments (Touchaleaume et al., 2016). Plastic fragments may persist in the soil as contaminants for more than 100 years, can have negative impacts on the food chain, and reduce crop yield and quality (Steinmetz et al., 2016). Plastic pollution in agricultural soils is an emerging environmental concern, requiring strong, science-based policy interventions to alleviate the problem (Brodhagen et al., 2017; de Souza Machado et al., 2018; Rillig et al., 2017; Sintim and Flury, 2017). In addition, PE mulches can cause air, water, and soil pollution during the process of disposal or incineration if not completely removed from the soil.

Given the pervasive nature of plastic pollution along with uncertain and complex policy solutions (Brodhagen et al., 2017), innovative approaches and new technologies for controlling pollution and preserving soil quality are being considered. $\mathrm{BDMs}$, produced from biodegradable polymers (such as starch or cellulose), have been proposed as a sustainable and environmentally friendly alternative to conventional petroleum-based mulches. ASTM International (2011) defines BDMs as a type of plastic material that degrades as a result of the actions of naturally occurring microorganisms, such as bacteria, fungi, and algae. In addition, the International Organization for Standardization (2012) and ASTM D5988 (ASTM International, 2003)

\begin{tabular}{llll}
\hline $\begin{array}{l}\text { Units } \\
\begin{array}{l}\text { To convert U.S. to SI, } \\
\text { multiply by }\end{array}\end{array}$ & U.S. unit & SI unit & $\begin{array}{l}\text { To convert SI to U.S., } \\
\text { multiply by }\end{array}$ \\
\hline 0.3048 & $\mathrm{ft}$ & $\mathrm{m}$ & 3.2808
\end{tabular}


state that BDMs are designed to biodegrade completely within 2 years, with $90 \%$ of their mass released as carbon dioxide and water, and the remaining $10 \%$ residing in the soil as microbial biomass. Use of BDMs reduces disposal efforts, because this innovative form of mulch degrades in the field (Briassoulis, 2007; Brodhagen et al., 2017; Corbin et al., 2013). At the end of the crop cycle, BDMs have the advantage of being incorporated directly into the soil, or into a composting system, where they should undergo biodegradation by soil microorganisms (Moreno and Moreno, 2008). Furthermore, using BDMs may also reduce or eliminate disposal time and associated labor and disposal costs.

In general, agricultural producers have incentives to adopt new technologies such as BDMs to reduce their environmental impact, improve their management practices by enhancing their technical efficiency, and increase the profitability of their production activity. For example, Jaeck and Lifran (2014) measured the valuation of attributes characterizing farming technology and found that most rice (Oryza sativa) growers from Camargue, France, were more willing to adopt environmentally friendly practices. In addition, banana (Musa acuminata) farmers were willing to adopt agroecological innovations to make their cropping systems more sustainable; these researchers also demonstrated that the economic attributes of innovation are the key determinants of adoption decisions (Blazy et al., 2011). Fresh apple (Malus $\times$ domestica) growers are willing to adopt precision agricultural technologies to improve the efficiency of agricultural production systems and the yield consistency of high-quality fruit (Gallardo et al., 2019). In this study, we examined the preferences of farmers and other agricultural participants for BDM attributes that impact the environment and profitability.

Understanding the underlying factors that contribute to consumer WTP for environmentally friendly and sustainable products helps agricultural producers gauge whether the returns will outweigh the costs of adoption. A 10\% premium for strawberries (Fragaria $\times$ ananassa) grown with BDMs could be obtained from
U.S. consumers (Chen et al., 2019). Consumers were willing to pay a $5 \%$ premium for eco-labeled apples (Loureiro et al., 2001) and premium prices for wheat (Triticum aestivum)derived products (flour and bread) that were produced by adopting an ecologically friendly postharvest technique (Wongprawmas et al., 2016).

In this exploratory study, we investigated the perceptions among agricultural participants (e.g., farmers, crop advisors, educators, and others) about the adoption of BDMs using choice experiments (Carroll et al., 2013; Gallardo et al., 2015; Hoke et al., 2014; Onken et al., 2011; Shi et al., 2011; Yue and Tong, 2009; Zhang et al., 2010). We selected a set of attributes that explain, in part, the willingness to adopt BDM products, including a premium for crops grown with BDMs, soil health, percentage of plastic residue left in the field after a harvesting season, and material costs. Our selection process for these attributes relied on the advice of field experts - including experienced farmers, mulch manufacturers, crop advisors, scientists, extension specialists, and other stakeholders. In addition to their guidance, we followed methods used in other studies for selecting attributes and associated levels of BDMs. Chen et al. (2019) showed that consumers are willing to pay $10 \%$ more on average for strawberries grown on BDMs. Miles et al. (2012) indicated that the range of the portion of mulch residue in the field after harvest is between $5 \%$ and $30 \%$ from four different BDMs used with tomatoes. Bandopadhyay et al. (2018) pointed out that soil health is a key component of agroecosystem sustainability in measuring the effects of BDMs on crop productivity and soils. Goldberger et al. (2019) examined growers' propensity to adopt BDMs on a nationwide basis. They suggested that strawberry growers' likelihood of adopting BDMs in the future varies by region. However, they did not specifically address growers' adoption incentives based on the different attributes of BDMs. Our study, therefore, fills this gap by identifying growers' WTP for different attributes of BDMs, and how other stakeholders, such as processing companies, farming consultants, and extension specialists, evaluate these BDM attributes. To conclude, the selected attributes and their associated levels are reasonable assumptions based on previous studies and our experiences working with the field experts.

\section{Materials and methods}

Experimental DEsign. We created a survey with six discrete choice scenarios to determine WTP among agriculture participants for various attributes of BDMs. The survey comprised 10 questions about farm operations, experience with plastic mulches and BDMs, risk preferences, sociodemographic characteristics, and other factors that might influence BDM purchase decisions.

We conducted pretest sampling in the state of Washington before 1 Nov. 2018 by selected farmers and crop advisors to improve the original survey. The survey was then administered to participants at the Pacific Northwest Vegetable Association (PNVA) Annual Conference at Kennewick, WA, and the Washington Small Fruit (WASF) Annual Conference at Lynden, WA, in Nov. 2018. Specifically, we gave a presentation, "Biodegradable Plastic Mulches for Profitability in Agricultural Applications," at both events. The first part of the presentation provided the background and key results of our two previous studies, including the economic feasibility of on-farm adoption of BDMs, with pumpkin production in Washington as a case study; and an evaluation of consumer preferences for an agricultural product grown on BDMs. The second part of the presentation used an audience survey to gain an understanding of the participants' current practice/knowledge of using plastic mulch and factors that affect their willingness to adopt BDMs.

DATA ACQuisition. A total of 81 survey responders participated-63 from the PNVA session and 18 from the WASF session. However, 17 responses were eliminated because of incomplete survey responses, resulting in 64 usable surveys.

We used polling technology (TurningPoint, Youngstown, OH) to capture real-time responses from agricultural crop producers, crop advisors, educators, extension agents, and others in the agricultural supply chain who attended the presentations (hereafter referred to as agricultural participants). The TurningPoint 
polling system has a multiple-choice response format with a maximum of 10 response alternatives. This approach allowed respondents to select only one response per question. For each question presented, respondents used a device to indicate their answer, which was recorded electronically. The diversity of participants allowed us to examine how preferences may vary across different stakeholders in the U.S. agricultural industry.

Before beginning the survey, we provided agricultural participants with an individual electronic keypad or clicker, and instructions and demonstrations about how to use the clickers. We read each question to the agricultural participants, then polling (time to answer the question) was opened for 10 to $20 \mathrm{~s}$. The system displayed a graphic representation of the responses immediately after the polling closed. The survey included six discrete choice scenarios and 10 questions about farm operations, as mentioned earlier. Note that nonfarmer respondents (e.g., crop advisors, educators, researchers, extensionists, and others) answered questions relating to farm business characteristics by selecting the option "not applicable."

Previous studies have highlighted the benefits of using audience survey technology such as the clickers in research, including the ability to survey larger groups, elimination of data entry errors, ease of use, and decreased time when compared with traditional survey methods (Powe et al., 2009). The technology has been shown to be a reliable method of data collection that increases audience engagement (Hall et al., 2005; McCarter and Caza, 2009).

The section of the survey on discrete choice scenarios presented different situations for adopting
BDMs. Each scenario offered two choice options (A and B), representing different combinations of changes in crop price, portion of plastic residue in the field at the end of the growing season (before tilling into soil), soil health, and mulch cost per $1000 \mathrm{ft}$ (linear) of mulch. Respondents were asked to choose one option from each choice set. If neither option was of interest, respondents could choose a third option, which was "opt out" (option C), presented as conventional plastic mulch. An example of the choice experiment is shown in Table 1.

Attributes and levels associated with BDMs, including two levels for consumer price premium, plastic residue, and soil health are presented in Table 2. The three levels of mulch cost were selected in the choice scenarios following the price range of BDMs (Chen et al., 2018). Altogether, there was a total of 24 (i.e., $2^{3} \times 3$ ) possible combinations. Because it was not possible to include every combination of BDM attributes, we developed a fractional factorial design for choice sets (Louviere et al., 2000) with statistical software (JMP 8; SAS Institute, Cary, NC). We used the main effects BDM fractional factorial design to select 12 choice options randomly [that maximized the D-efficiency score (80.2) according to Ferrini and Scarpa (2007), but see Kuhfeld (2005), Lusk and Norwood (2005), Nijs (2019), and Pambo et al. (2015)] from the remaining set, including six choice scenarios, each consisting of two pairwise choices (options A and B).

DisCRETE CHOICE MODEL OF BDM PREFERENCES. Discrete choice experiments provide an incentive for participants to reveal their true preferences and are increasingly used in marketing to estimate participants'
WTP values for product attributes (Alfnes, 2004; Carlsson and Martinsson, 2001; Lusk and Schroeder, 2004). Multinomial logit models and conditional logit models have been widely used as the standard techniques to analyze discrete choice data (Greene and Hensher, 2010). However, those models impose the independence of irrelevant alternatives assumption. Therefore, we introduce the mixed logit model, which can relax this assumption by modeling preference heterogeneity, to estimate discrete choice random utility models (Alfnes, 2004; McFadden and Train, 2000; Revelt and Train, 1998; Train, 2003, 2009; Zheng et al., 2016). It has been widely used to study consumer, market intermediary, and grower preferences for genetically modified foods, fruit quality attributes, fruit traits, and other products (Gallardo et al., 2015; Lusk et al., 2005; Yue et al., 2017). In this study, we used the mixed logit model to calculate agricultural participants' WTP for BDM attributes.

The Mixed LOgit MODEL (EMPIRICAL). Choice modeling is based on the premise that an underlying rational decision-making process is used for individual choices and is therefore appropriate for modeling our survey results and for determining the individual characteristics that might have an influence on the decision making used in selecting a choice set. In this study, we applied a discrete choice experiment model to estimate respondents' WTP for various BDM attributes. In particular, our model used consumer random utility theory, which can be extended easily to farmer decisions (Lusk and Hudson, 2004). The random utility for individual $i$ in choosing a choice set containing $Q$ alternatives $(j=1,2$, ..., Q) to maximize its expected utility of profit from the $j$ th alternative

Table 1. Biodegradable plastic mulch (BDM) choices and attributes presented to the respondents of the 2018 survey of the Pacific Northwest U.S. agricultural sector on the use of BDMs.

\begin{tabular}{|c|c|c|c|}
\hline BDM attributes & Option A (BDMs) & Option B (BDMs) & Option $\mathrm{C}^{\mathrm{z}}$ \\
\hline $\begin{array}{l}\text { Portion of mulch residue in field at end of season } \\
\text { (before tilling into soil) }\end{array}$ & $5 \%$ & $30 \%$ & \\
\hline Soil health & No effect & $10 \%$ decrease & \\
\hline Mulch cost [per $1000 \mathrm{ft}$ (linear) of mulch] $]^{\mathrm{y}}$ & $\$ 120$ & $\$ 80$ & \\
\hline Which option would you choose? & $\square$ & $\square$ & $\square$ \\
\hline
\end{tabular}


Table 2. Description, attribute, and associated levels of biodegradable plastic mulches (BDMs) defined in the 2018 survey of the Pacific Northwest U.S. agricultural sector.

\begin{tabular}{lll}
\hline Attribute & \multicolumn{1}{c}{ Levels } \\
\hline Consumer premium & No change, $10 \%$ premium & Change in crop price when growing a crop on BDM \\
Plastic residue & $5 \%, 30 \%$ & Percentage of plastic residue left in the field after harvesting \\
Soil health & No effect, $10 \%$ decrease & Refers to soil quality \\
Cost & $\$ 80, \$ 120, \$ 160^{\mathrm{z}}$ & Dollars per $1000 \mathrm{ft}[304.8 \mathrm{~m}($ linear $)]$ of mulch \\
\hline
\end{tabular}

${ }^{{ }^{2}} \$ 1 / 1000 \mathrm{ft}=\$ 0.3281 / 100 \mathrm{~m}$.

can be represented by the following utility function:

$$
U_{i j}=\beta_{i} X_{i j}+\varepsilon_{i j}
$$

where $X_{i j}$ is the deterministic component of the utility function $U_{i j}, \beta_{i}$ is an unobserved random coefficient vector for each individual $i$ that varies in the population, and $\varepsilon_{i j}$ is the random error that captures unsystematic or unobserved random elements of individual $i$ 's choice and is assumed to be an independently and identically distributed Gumbel distribution (extreme value).

It is important to evaluate heterogeneity in the decision-making process because consumers often show heterogeneous preferences unrelated to observable characteristics (Lusk et al., 2003; Ouma et al., 2007; Tonsor et al., 2009). Therefore, we used a mixed logit model to estimate producer WTP for the BDM attributes. We were interested in how respondents valued BDM attributes differently across different segments (farmers, crop advisors, educators, and others), which may reveal preference heterogeneity on product attributes by producers and their associates (Campbell et al., 2013; Gallardo et al., 2015; Ouma et al., 2007).

This choice probability can be about calculated through simulation (Brownstone and Train, 1998). The indirect utility $X_{i j}$ can be written as

$$
X_{i j}=\delta_{i} A S C_{j}+\sum_{j=1}^{Q} \alpha_{i} S_{i j}+\varepsilon_{i j},
$$

where $\delta$ is the vector of costs for each alternative $j, \alpha$ is the vector of coefficients for individual $i$ 's characteristics and $Q \mathrm{BDM}$ attributes for option $j, A S C_{j}$ is the alternative specific constant representing the utility provided by option $j$ not explained by rating variations $(j=$ option $\mathrm{A}$ or $j=$ option B, etc.), $S_{i j}$ represents the ratings of individual $i$ 's characteristics (e.g., the most important factor affecting BDM purchasing decision, on-farm revenue, risk, etc.) and for $Q$ attributes as presented in option $j$ to individual $i$, and $\varepsilon_{i j}$ is the error term.

A change in a single BDM attribute is interpreted as the marginal willingness to pay (MWTP) estimate. Following Train's (2003) study, the MWTP for an attribute can be calculated as the ratio of the attribute coefficient to the price coefficient as follows:

$$
\operatorname{MWTP}_{k}=-\frac{\beta_{k}}{\beta_{p}},
$$

where $M W T P_{k}$ is the MWTP for the $k$ th $\mathrm{BDM}$ attribute, $\beta_{k}$ is a parameter estimate for the $k$ th attribute, and $\beta_{p}$ is a parameter estimate for the mulch cost from the mixed logit estimation. The SD for each MWTP was estimated by simulating 1000 random observations from a multivariate normal distribution for each parameter estimated. For each of these 1000 observations, the MWTP was calculated following Eq. [3], generating an empirical distribution (Krinsky and Robb, 1986).

Pooled model. Pooled models are useful for analyzing the collective responses of a group, whereas segmented models allow analysis by subgroup. We used a pooled model to better understand the WTP for BDM attributes of the entire group of respondents and to determine the value estimates for each attribute. We then clustered the respondents according to sociodemographic and other characteristics to understand more fully their specific attitudes within a particular subgroup.

Using the pooled model, we aggregated responses for each of three BDM attributes. The three attributes we used were consumer premium, plastic residue, and soil health. We converted each into a dichotomous variable to capture the preference. Dollar values [per 1000 $\mathrm{ft}$ (linear)] for the cost of mulch were $\$ 80, \$ 120$, and $\$ 160$ (e.g., the cost of mulch per $1000 \mathrm{ft}$ is equal to the cost of a roll of mulch with dimensions $4 \times$ $4000 \mathrm{ft}$ divide by 4 ) within the market price range of BDMs (Chen et al., 2018). In addition, we estimated the probability of selecting a particular alternative as a function of choicespecific attributes and an alternative specific constant (ASC). Because our choice experiment involved "conventional (PE) plastic mulch" options, the ASC was not choice specific, but was equal to " 1 " if either $\mathrm{A}$ or $\mathrm{B}$ was chosen, and " 0 " if $\mathrm{C}$ was selected.

Segmented models. We used a segmented model to analyze answers by subgroups within the respondent population. Purchasing decisions of the respondents varied across three groups: farmers, crop advisors, and "others" (educators, researchers, extension agents, and others in the agricultural supply chain). Because we had 25\% farmers and $30 \%$ crop advisors, accounting for $55 \%$ of all respondents in this study, we chose to compare the withingroup decisions across other groups. Thus, we ran the mixed logit model separately across different groups.

\section{Results and discussion}

Data Description. Table 3 presents summary statistics and descriptions of explanatory variables for the 64 respondents. Every respondent was asked to give responses to six scenarios, yielding 384 responses. Because each scenario comprised three choice options, 1152 observations were generated, and the exclusion of 36 invalid observations resulted in a total of 1116 observations. The study sample included 16 farmers and 19 crop advisors. In practice, although respondents could be both crop advisors and farmers, they were only allowed to identify themselves as either crop advisor or 
Table 3. Frequency table of experience with polyethylene (PE) mulches and biodegradable plastic mulches (BDMs), the most important factor for using BDMs, years of production, and demographic characteristics for respondents recruited from the 2018 survey of the Pacific Northwest U.S. agricultural sector $(\mathrm{n}=64) .^{\mathrm{z}}$

\begin{tabular}{|c|c|c|}
\hline Variable & Description & $\begin{array}{c}\text { Frequency } \\
(\%)\end{array}$ \\
\hline \multirow[t]{4}{*}{ Occupation } & Farmer & 25.0 \\
\hline & Educator (research, extension) & 15.6 \\
\hline & Crop advisor & 29.7 \\
\hline & Other & 29.7 \\
\hline \multirow[t]{5}{*}{ Knowledge about BDMs } & Not at all familiar & 25.0 \\
\hline & Slightly familiar & 43.8 \\
\hline & Moderately familiar & 14.1 \\
\hline & Very familiar & 10.9 \\
\hline & Not sure & 6.2 \\
\hline \multirow[t]{2}{*}{ Have you ever used PE mulch? } & Yes & 34.4 \\
\hline & Otherwise & 65.6 \\
\hline \multirow[t]{2}{*}{ Have you ever used BDMs? } & Yes & 12.5 \\
\hline & Otherwise & 87.5 \\
\hline \multirow[t]{7}{*}{ Years of production } & $<1$ & 6.3 \\
\hline & $1-5$ & 17.2 \\
\hline & $6-10$ & 6.3 \\
\hline & $11-15$ & 6.3 \\
\hline & $16-20$ & 3.1 \\
\hline & $>20$ & 20.3 \\
\hline & Not applicable & 40.5 \\
\hline \multirow[t]{10}{*}{ Gross on-farm revenue in 2018} & $>\$ 25,000$ & 7.8 \\
\hline & $\$ 25,000-\$ 49,999$ & 1.6 \\
\hline & $\$ 50,000-\$ 74,999$ & 0.0 \\
\hline & $\$ 75,000-\$ 99,999$ & 0.0 \\
\hline & $\$ 100,000-\$ 249,999$ & 9.4 \\
\hline & $\$ 250,000-\$ 499,999$ & 3.1 \\
\hline & $\$ 500,000-\$ 999,999$ & 1.6 \\
\hline & $\$ 1,000,000-\$ 2,499,999$ & 6.3 \\
\hline & $>\$ 2,500,000$ & 14.1 \\
\hline & Not applicable & 56.1 \\
\hline \multirow[t]{8}{*}{ Most important factor for using BDMs } & Cost of BDM material & 20.3 \\
\hline & Labor cost savings & 14.1 \\
\hline & Increase in crop production & 6.3 \\
\hline & Potential price premium of crop & 3.1 \\
\hline & Benefits of tilling BDM into field & 12.5 \\
\hline & Visual appearance after harvest & 3.1 \\
\hline & Improved soil health & 18.8 \\
\hline & Other & 21.8 \\
\hline
\end{tabular}

${ }^{2}$ Participants in the agricultural sector include farmers, crop advisors, educators, researchers, extension specialists, and others.

farmer at the time of filling out the survey. Most respondents (69\%) were familiar with BDMs. In the past, $34 \%$ and $13 \%$ of the respondents had used PE mulches and BDMs, respectively, either in crop production or on test plots. About $33 \%$ of respondents had been involved in crop production as a farm owner, manager, or primary decision maker for more than 5 years, and $36 \%$ of participants generated gross on-farm revenue of at least $\$ 100,000$ in 2018 . When considering the use of BDM in the field, $20 \%$ and
$19 \%$ of respondents, respectively, indicated that the cost of BDM material and improved soil health were the most important factors. Among subgroups, $25 \%$ of farmers indicated that benefits of tilling BDM into the field or having the option of tilling it into the field was the most important factor, $26 \%$ of crop advisors indicated that both the cost of BDM material and improved soil health were the most important factors, and $24 \%$ of other respondents indicated that improved soil health was the most important factor. We are also interested in the respondents' perception of risk-taking behavior, which was measured on a 9-point Likert scale [from 1 = "extremely unwilling to take risk" to 9 = "extremely willing to take risk" ( $\mathrm{Li}$ and McCluskey, 2017)]. More than half (56\%) the respondents in our sample indicated they were willing to take some risk (production and/or financial). Selected explanatory variables and abbreviations used in the survey, along with short descriptions, are presented in Table 4.

Pooled MOdels. We used pooled models, in which all respondents are treated as if they are in one homogeneous group, as the benchmark to evaluate the overall effect of BDM attributes. Table 5 presents the results from a mixed logit model, with BDM attributes in model 1 and BDM attributes and respondents' characteristics in model 2. According to the Akaike information criterion value [a statistical technique for model selection criteria based on the lowest value of information loss (Akaike, 1974)], model 2 fit the data better than model 1 , inferring that respondent characteristics might influence the choice set. ASC showed a significantly positive effect at the $10 \%$ level, implying that participants exhibited a strong preference for BDM. In models 1 and 2, the cost parameter was negative and significant at the $5 \%$ level, implying that when the cost of BDM increased, the respondent was less likely to purchase it. Consumer price premium was positive and statistically different at the $1 \%$ significance level, indicating that respondents were willing to adopt BDM when the crop commands a higher price premium from consumers.

In model 2 , soil health had a positive effect on WTP at the $10 \%$ significance level, implying participants were most likely to use BDMs if there was no change in soil health. This was consistent with previous findings of the positive effects of BDMs on soil health by Steinmetz et al. (2016) and Touchaleaume et al. (2016). For plastic residue, there was a negative effect at the $1 \%$ significance level, in that respondents were less likely to choose BDMs when there was a greater portion of plastic residue left in the field after the harvesting season than a lesser portion. Furthermore, the 
Table 4. Selected variables and descriptions for biodegradable plastic mulch (BDM) users and nonusers based on the 2018 survey of the Pacific Northwest U.S. agricultural sector. ${ }^{\mathrm{z}}$

\begin{tabular}{ll}
\hline Variable & \multicolumn{1}{c}{ Description } \\
Farmer & $1=$ respondents are farmers, $0=$ otherwise \\
Advisor & $1=$ respondents are crop advisors, $0=$ otherwise \\
Cost importance & $1=$ cost of BDM material is the most important factor, \\
& $0=$ otherwise \\
Experience & $1=$ more than 5 years of experience, $0=$ otherwise \\
Revenue & $1=$ revenue is no less than $\$ 100,000,0=$ otherwise \\
Risk & $1=$ risk-taking $($ level of risk: 5 or more $), 0=$ otherwise \\
\hline
\end{tabular}

${ }^{\mathrm{z}}$ Participants in the agricultural sector include farmers, crop advisors, educators, researchers, extension specialists, and others.

SDs for soil health and plastic residue were statistically significant at the $1 \%$ level, which reflects heterogeneous preferences for soil health and plastic residue.

For respondents' characteristics variables in model 2 , our results indicate that cost-sensitive respondents who placed the cost of material as the most important factor when considering the use of BDMs were less likely to adopt BDMs at the $1 \%$ significance level. Respondents who were risktakers were willing to pay more for BDMs at the $1 \%$ significance level. These results are consistent with other studies (Bond and Wonder, 1980; Franken et al., 2014).

Table 5. Estimates of attributes of biodegradable plastic mulches (BDMs) for mixed logit model 1 and estimates of selected variables of BDMs for mixed logit model 2 based on the 2018 survey of the Pacific Northwest U.S. agricultural sector $(\mathrm{n}=64)$. $^{\mathrm{z}}$

\begin{tabular}{|c|c|c|c|c|}
\hline \multirow[b]{2}{*}{ Variable $^{y}$} & \multicolumn{2}{|c|}{ Model 1} & \multicolumn{2}{|c|}{ Model 2} \\
\hline & Estimate & SE & Estimate & SE \\
\hline \multicolumn{5}{|l|}{ Mean } \\
\hline Cost & $-0.013^{* *}$ & 0.007 & $-0.013 * *$ & 0.007 \\
\hline ASC & $1.559^{*}$ & 0.942 & 1.344 & 0.972 \\
\hline Consumer premium & $1.209 * * *$ & 0.248 & $1.203^{* * *}$ & 0.252 \\
\hline Plastic residue & $-1.147 * * *$ & 0.324 & $-1.129 * * *$ & 0.322 \\
\hline Soil health & 0.667 & 0.419 & 0.731 * & 0.416 \\
\hline ASC $\times$ cost importance & & & $-1.095 * * *$ & 0.423 \\
\hline ASC $\times$ revenue & & & -0.407 & 0.380 \\
\hline ASC $\times$ risk & & & $1.012 * * *$ & 0.360 \\
\hline \multicolumn{5}{|l|}{ SD } \\
\hline Consumer premium & 0.255 & 0.744 & 0.376 & 0.382 \\
\hline Plastic residue & $1.609 * * *$ & 0.291 & $1.620 * * *$ & 0.292 \\
\hline Soil health & $1.004^{* * *}$ & 0.330 & $0.838 * * *$ & 0.334 \\
\hline Log likelihood & \multicolumn{2}{|c|}{-325.903} & \multicolumn{2}{|c|}{-318.380} \\
\hline AIC & \multicolumn{2}{|c|}{667.805} & \multicolumn{2}{|c|}{658.761} \\
\hline $\mathrm{BIC}$ & \multicolumn{2}{|c|}{707.945} & \multicolumn{2}{|c|}{713.953} \\
\hline
\end{tabular}

${ }^{\mathrm{z}}$ Participants in the agricultural sector include farmers, crop advisors, educators, researchers, extension specialists, and others; 1116 observations.

"ASC = alternative specific constant (ASC is equal to " 1 " if either options A or B was chosen, and " 0 " if option C was selected); $\mathrm{AIC}=$ Akaike information criterion (a statistical technique for model selection criteria based on the lowest AIC value of information loss); $\mathrm{BIC}=$ Bayesian information criterion (another statistical technique for model selection criteria based on the lowest BIC value of information loss).

${ }^{*},{ }^{* *},{ }^{* *}$ Significant at $P \leq 0.10,0.05$, or 0.01 , respectively. approach. Pairwise $t$ tests were used to determine whether there were statistically significant differences in preferences across different groups (Tables 6 and 7). We also applied a likelihood ratio (LR) test of the pooled vs. subgroup (or segmented) models, with the null hypothesis that the regression coefficients are equal across the different groups (Croarkin and Tobias, 2006; Freund et al., 2010; Meloun and Militky, 2011). The LR test results strongly rejected the null hypothesis at the $1 \%$ level, which means the pooled model is rejected in favor of the individual segmented models [model 1, Table 6: $\mathrm{LR}$ (farmers) $=25.47, \mathrm{LR}$ (crop advisors $)=33.49, \chi^{2}$ critical value $=$ 20.09; model 2, Table 7: LR(farmers) $=25.6, \mathrm{LR}($ crop advisors $)=33.27, \chi^{2}$ critical value $=24.73$ ] .

Results are first reported by subgroup without individual characteristics of the participants (Table 6). The cost parameter was negative and significant at the $5 \%$ level in the "other" group, but insignificant in farmers and crop advisors (Table 6). From our conversation with farmers, we have found they are more concerned with how the additional cost enables them to generate additional revenues, and not with the cost itself. We consider the resulting change in potential revenues that affects their WTP and adopt BDMs, because adoption allows them to market their products as more environmentally friendly than those of rival farms and thereby generate a premium for their products. In this case, the cost per pound of output is very small compared with the potential revenue gained. So, although farmers are concerned about costs relatively, it is net profit (= Revenue - Costs) that keeps them in business. Stated another way, if growers focus only on costs, they will be unable to take advantage of revenue opportunities and will likely have an unsustainable business model. This result implies that those who were neither farmers nor crop advisors placed more emphasis on the cost of the BDM material when they considered the use of BDMs.

The consumer premium coefficient was statistically significant across all segments, indicating respondents were willing to select BDMs when receiving a price premium for a crop grown on BDMs. Also, for soil health, crop advisors exhibited positive and 
Table 6. Estimates of mixed logit model 1 and pairwise $t$ test comparison for attributes of biodegradable plastic mulches (BDMs) by subgroup based on the 2018 survey of the Pacific Northwest U.S. agricultural sector. ${ }^{\mathrm{z}}$

\begin{tabular}{|c|c|c|c|c|c|c|}
\hline \multirow[b]{2}{*}{ Variable $^{\mathrm{y}}$} & \multicolumn{3}{|c|}{ Coefficient [estimate (SE)] } & \multicolumn{3}{|c|}{$t$ Tests of comparisons ${ }^{x}$} \\
\hline & Farmers (F) & Crop advisors (A) & Others $(\mathbf{O})$ & F-A & F-O & $\mathrm{A}-\mathrm{O}$ \\
\hline \multicolumn{7}{|l|}{ Mean } \\
\hline Cost & $-0.005(0.012)$ & $-0.015(0.016)$ & $-0.020 * *(0.009)$ & $0.010 * *$ & $0.015 * * *$ & 0.005 \\
\hline ASC & $0.647(1.800)$ & $0.868(2.187)$ & $2.737 * *(1.367)$ & -0.221 & $-2.090 * * *$ & $-1.869 * * *$ \\
\hline Consumer premium & $1.067 * *(0.458)$ & $2.044 * * *(0.632)$ & $1.036^{* * *}(0.368)$ & $-0.977 * * *$ & 0.031 & $1.008 * * *$ \\
\hline Plastic residue & $-1.196 * *(0.562)$ & $-1.492(0.766)$ & $1.370 * * *(0.471)$ & 0.296 & $-2.566 * * *$ & $-2.862 * * *$ \\
\hline Consumer premium & $0.602(0.588)$ & $0.354(0.915)$ & $-0.444(0.366)$ & & & \\
\hline Plastic residue & $1.098 * *(0.471)$ & $2.685^{* * *}(0.787)$ & $1.502 * * *(0.399)$ & & & \\
\hline Soil health & $0.640(0.564)$ & $1.681 * *(0.772)$ & $1.151 * * *(0.475)$ & & & \\
\hline Log likelihood & -86.519 & -81.393 & -149.621 & & & \\
\hline AIC & 189.038 & 178.786 & 315.241 & & & \\
\hline $\mathrm{BIC}$ & 218.173 & 209.179 & 349.022 & & & \\
\hline
\end{tabular}

${ }^{\mathrm{z}}$ Participants in the agricultural sector include farmers, crop advisors, educators, researchers, extension specialists, and others.

${ }^{\mathrm{y}}$ ASC $=$ alternative specific constant (ASC is equal to " 1 " if either options A or B was chosen, and " 0 " if option C was selected); AIC = Akaike information criterion (a statistical technique for model selection criteria based on the lowest AIC value of information loss); BIC = Bayesian information criterion (another statistical technique for model selection criteria based on the lowest BIC value of information loss).

${ }^{\mathrm{x}}$ Pairwise $t$ test comparison of BDM attribute coefficients (netting out the omitted category) across groups.

${ }^{*},{ }^{* *},{ }^{* *}$ Significant at $P \leq 0.10,0.05$, or 0.01 , respectively.

significantly different effects, implying they were more attentive to soil health than the other groups. Participants in our sample exhibited different attitudes toward the degradation of BDMs in the soil (which can take a few years). For soil health, however, farmers exhibited homogeneous preferences, which means their attitudes toward the maintenance of soil health did not exhibit statistically significant differences, whereas the within-group preferences of crop advisors, nonfarmers, and noncrop advisors varied significantly.

Considering individual characteristics across segments, our findings show that cost was negative and significant at the $1 \%$ level for crop advisors, suggesting they were more cost focused than other groups (Table 7). In addition, the risk variable was positive and significant for farmers and others, indicating that the participants who were more willing to take risks were more likely to choose BDMs, except for crop advisors.

Table 7. Estimates of mixed logit model 2 and pairwise $t$ test comparison for attributes of biodegradable plastic mulches and characteristics of the participants by subgroup based on the 2018 survey of the Pacific Northwest U.S. agricultural sector. ${ }^{\mathrm{z}}$

\begin{tabular}{|c|c|c|c|c|c|c|}
\hline \multirow[b]{2}{*}{ Variable $^{\mathrm{y}}$} & \multicolumn{3}{|c|}{ Coefficient [estimate (SE)] } & \multicolumn{3}{|c|}{$t$ Tests of comparisons $s^{\mathrm{x}}$} \\
\hline & Farmers (F) & Crop advisors (A) & Others $(\mathrm{O})$ & F-A & F-O & A-O \\
\hline \multicolumn{7}{|l|}{ Mean } \\
\hline ASC & $-0.903(1.926)$ & $0.947(2.123)$ & $2.415 *(1.402)$ & $-1.850 * * *$ & $-3.318 * * *$ & $-1.468 * * *$ \\
\hline Consumer premium & $1.063^{* * *}(0.426)$ & $1.745^{* * *}(0.576)$ & $1.024 * * *(0.367)$ & $-0.682 * * *$ & 0.039 & $0.721 * * *$ \\
\hline Plastic residue & $-1.130 * *(0.532)$ & $-0.718(0.714)$ & $-1.344 * * *(0.461)$ & $-0.412 * *$ & -0.214 & $0.626 * * *$ \\
\hline ASC $\times$ revenue & $0.365(0.926)$ & $0.017(0.900)$ & $-0.841(0.706)$ & 0.348 & $1.206 * * *$ & $0.858 * * *$ \\
\hline ASC $\times$ risk & $1.948 * * *(0.663)$ & $-0.065(0.808)$ & $1.180 * *(0.539)$ & $2.013 * * *$ & $0.768 * * *$ & $-1.245^{* * *}$ \\
\hline \multicolumn{7}{|l|}{ SD } \\
\hline Consumer premium & $0.020(0.948)$ & $0.043(0.589)$ & $0.456(0.390)$ & & & \\
\hline Plastic residue & $1.067 * *(0.459)$ & $2.324 * * *(0.701)$ & $1.428 * * *(0.390)$ & & & \\
\hline Observations (n) & 282 & 330 & 504 & & & \\
\hline
\end{tabular}

${ }^{\mathrm{z}}$ Participants in the agricultural sector include farmers, crop advisors, educators, researchers, extension specialists, and others.

"ASC = alternative specific constant (ASC is equal to "l" if either option A or B was chosen, and "0" if option C was selected); AIC = Akaike information criterion (a statistical technique for model selection criteria based on the lowest AIC value of information loss); BIC = Bayesian information criterion (another statistical technique for model selection criteria based on the lowest BIC value of information loss).

${ }^{x}$ Pairwise $t$ test comparison of BDM attribute coefficients (netting out the omitted category) across groups.

${ }^{*},{ }^{* *},{ }^{* *}$ Significant at $P \leq 0.10,0.05$, or 0.01 , respectively. 
Predicted MWTP. Applying the estimated coefficients from Eq. [3], we calculated MWTP values for BDM attributes according to Train (2003). The results indicate that respondents were willing to pay a premium of $\$ 93.06$ per $1000 \mathrm{ft}$ of mulch if the selling price for BDM-grown crops is increased by $10 \%$. In addition, respondents indicated a diminished value of $\$ 87.36$ per $1000 \mathrm{ft}$ of mulch if the portion of mulch residue left in the field after the end of the season (i.e., before tilling into soil) increased from $5 \%$ to $30 \%$. Furthermore, participants were willing to pay a premium of $\$ 56.54$ per $1000 \mathrm{ft}$ of mulch if the levels of soil health changed from a decrease of $10 \%$ to no significant decrease. In sum, the greatest WTP value was assigned to the consumer price premium, which indicates that price premiums consumers may be willing to pay for products grown on BDMs should be factored into agricultural growers' calculations. (Note that currently there are no labels or price premiums associated with products grown using BDMs.) This research suggests agricultural participants assign the highest value to BDM attributes that enhance profitability or soil health, or that reduce field-borne residue.

Our results show that cost was significant to other agricultural participants, such as educators and extension agents, but not necessarily to farmers who made decisions based on profit per unit of output. Based on our discussions with the field experts, farmers are usually interested in their overall profits. In a study by Chen et al. (2019), the authors concluded that consumers were willing to pay a $10 \%$ premium on average for strawberries grown on BDMs. Using a partial budget analysis of adopting BDMs in strawberry production in Washington state, they found that the revenue from the price premium will cover the cost of BDMs and, along with reduced labor costs in plastic mulch removal and disposal, BDM adoption will generate a higher profit than using conventional mulch. This simple analysis helps in demonstrating that despite the higher purchase cost of BDMs, farmers can potentially realize greater net benefits resulting from labor cost savings and a price premium by adopting the technology. This result suggests that growers (and crop advisors) need to include both revenue (including price premiums) and costs, or profit, into decision making. That is, profit per unit of output is the defining decision-making criteria, and not simply cost per acre.

A limitation of an exploratory study is small sample size. In our study, we surveyed 64 respondents, which enabled us to draw statistical inferences in finite samples. Orme (2010) suggests that studies on specific markets can rely on small samples, and this sampling strategy is found in some recent articles, including those by Gallardo et al. (2009, 2018), Gallardo and Wang (2013), and $\mathrm{Li}$ et al. (2019).

Another limitation is the time constraint for answering each choice scenario using audience survey technology. McCarter and Caza (2009) consider the audience survey technology to be a reliable method of data collection. However, they point out that one challenge related to using this technology to conduct research is that the participants might not be able to answer questions at their own pace. To address this issue, we introduced the TurningPoint system with $\mathrm{i}$-clicker functions to the participants by presenting them with two practice questions on the first two slides of the survey presentation to warm up their response rate. Then, the actual survey followed with the six questions regarding farm operation. Before the choice scenarios, we presented two slides regarding four specific factors in six hypothetical scenarios and the potential benefits of BDMs. In each scenario, the participants had $20 \mathrm{~s}$ to select their answers (option A, B, or C) after we finished reading all the information on each slide.

\section{Conclusions}

The main purpose of this study was to make a first attempt to gather information about WTP for BDM attributes. We assessed agricultural participants' WTP for the adoption of BDMs in the agricultural supply chain and how these participants ranked the relative importance of different BDM attributes using discrete choice experiments. Using a mixed logit model, we assessed WTP for the adoption of BDMs and its functional attributes from 64 respondents from two Pacific Northwest U.S. regional conferences in Nov. 2018. We found that respondents were willing to pay a statistically significant premium for healthy soil and a lower fraction of plastic residue left in the field after harvest. Specifically, respondents who were more willing to take risks or who had fewer concerns about material costs were more likely to adopt BDM. Respondents assigned MWTP values of $\$ 93$ and $\$ 57$ per $1000 \mathrm{ft}$ of mulch when a $10 \%$ consumer price premium for crops grown on BDM was present and no change in soil health occurred, respectively. On the contrary, respondents discounted the MWTP value by $\$ 87$ per $1000 \mathrm{ft}$ of mulch if the fraction of mulch residue left in the field increased from $5 \%$ to $30 \%$ at the end of harvest (before tilling into soil).

Respondents' WTP differed across BDM attributes, but this could be expected because each participant had his or her own objectives and preferences. Specifically, the cost attribute was a greater concern to nonfarmers and noncrop advisors, whereas the soil health attribute was important to crop advisors. We are not implying farmers are unconcerned with cost, but that relative to cost they emphasized other factors of BDMs more strongly. Farmers must focus on profit per unit of output to stay in business, and must account for the combination of attributes that affect their profitability and sustainability. Crop advisors' and others' preferences for soil health were mixed relative to farmers.

Although our research addressed the needs of the agricultural sector in a specific region, our approach can be generalized to studies involving farmers and growers across the nation. We selected our samples based on the diversity of growers in the Pacific Northwest U.S. region. Because this is an exploratory study, the survey's samples enable us to provide firsthand evidence from the practitioners in the region.

To conclude, it is important to identify how new agricultural technology developments will affect WTP for the adoption of BDMs in the agricultural sector. From a practical perspective, we seek to understand how green technologies with positive externalities affect agricultural production 
when they are introduced into the market. From a social perspective, there is also a positive externality as plastic leakage into the terrestrial and water ecosystems is reduced. This study sheds light on the effect of technology on farming practices to promote the use of sustainable agricultural practices among farmers and growers. Policymakers can also make use of the results of our study to formulate policies aimed at supporting agricultural production, such as incentive programs for using biodegradable mulches, and guidelines on the use of nonbiodegradable plastics in mulches. Continued research and development of BDMs by academia and industry groups that seek to increase its productivity and to reduce its cost of production, as well as mitigate plastic pollution, will enable the commercialization of BDMs on a larger scale in the future.

\section{Literature cited}

Akaike, H. 1974. A new look at the statistical model identification. IEEE Trans. Automat. Contr. 19:716-723.

Alfnes, F. 2004. Stated preferences for imported and hormone-treated beef: Application of a mixed logit model. Eur. Rev. Agr. Econ. 31:19-37.

ASTM International. 2003. ASTM D 5988-03: Standard test method for determining aerobic biodegradation in soil of plastic materials or residual plastic materials after composting. ASTM International, West Conshohocken, PA.

ASTM International. 2011. ASTM D883-11: International standard terminology relating to plastics. ASTM International, West Conshohocken, PA.

Bandopadhyay, S., L. Martin-Closas, A.M. Pelacho, and J.M. DeBruyn. 2018. Biodegradable plastic mulch films: Impacts on soil microbial communities and ecosystem functions. Front. Microbiol. 9:819.

Blazy, J.M., A. Carpentier, and A. Thomas. 2011. The willingness to adopt agro-ecological innovations: Application of choice modelling to Caribbean banana planters. Ecol. Econ. 72:140-150.

Bond, G.E. and B. Wonder. 1980. Risk attitudes amongst Australian farmers. Austral. J. Agr. Econ. 24:16-34.

Briassoulis, D. 2007. Analysis of the mechanical and degradation performances of optimised agricultural biodegradable films. Polym. Degrad. Stabil. 92:1115-1132.
Brodhagen, M., J.R. Goldberger, D. Hayes, D.A. Inglis, T.L. Marsh, and C.A. Miles. 2017. Policy considerations for limiting unintended residual plastic in agricultural soils. Environ. Sci. Policy 69:81-84.

Brodhagen, M., M. Peyron, C.A. Miles, and D.A. Inglis. 2015. Biodegradable plastic agricultural mulches and key features of microbial degradation. Appl. Microbiol. Biotechnol. 99:1039-1056.

Brownstone, D. and K. Train. 1998. Forecasting new product penetration with flexible substitution patterns. J. Econ. 89:109-129.

Campbell, B.L., S. Mhlanga, and I. Lesschaeve. 2013. Consumer preferences for peach attributes: Market segmentation analysis and implications for new marketing strategies. Agr. Resour. Econ. Rev. 42:518-541.

Carlsson, F. and P. Martinsson. 2001. Do hypothetical and actual marginal willingness to pay differ in choice experiments? Application to the valuation of the environment. J. Environ. Econ. Mgt. 41:179192.

Carroll, K., J. Bernard, and J. Pesek. Jr. 2013. Consumer preferences for tomatoes: The influence of local, organic, and state program promotions by purchasing venue. J. Agr. Resour. Econ. 38:379396.

Chen, K.J., S.P. Galinato, S. Ghimire, S. MacDonald, T.L. Marsh, C.A. Miles, P.R. Tozer, and M.M. Velandia. 2018. Important considerations for the use of biodegradable mulch in crop production. Washington State Univ. Ext. Publ. FS304E.

Chen, K.J., T.L. Marsh, P.R. Tozer, and S.P. Galinato. 2019. Biotechnology to sustainability: Consumer preferences for food products grown on biodegradable mulches. Food Res. Intl. 116:200-210.

Corbin, A., J. Cowan, C.A. Miles, D. Hayes, J. Dorgan, and D.A. Inglis. 2013. Using biodegradable plastics as agricultural mulches. Washington State Univ. Ext. Publ. FS103E.

Croarkin, C. and P. Tobias. (eds.). 2006. NIST/SEMATECH e-handbook of statistical methods. 20 Feb. 2020. <http:// www.itl.nist.gov/div898/handbook>.

D'Alessandro, N. 2014. 22 Facts about plastic pollution (and 10 things we can do about it). 30 Aug. 2019. <https://www. ecowatch.com $/ 22$-facts-about-plasticpollution-and-10-things-we-can-doabout-it-1881885971.html>.

de Souza Machado, A.A., W. Kloas, C. Zarfl, S. Hempel, and M.C. Rillig. 2018.
Microplastics as an emerging threat to terrestrial ecosystems. Glob. Change Biol. 24:1405-1416.

Ferrini, S. and R. Scarpa. 2007. Designs with a priori information for nonmarket valuation with choice experiments: A Monte Carlo study. J. Environ. Econ. Mgt. 53:342-363.

Franken, J.R., J.M. Pennings, and P. Garcia. 2014. Measuring the effect of risk attitude on marketing behavior. Agr. Econ. 45:525-535.

Freund, R.J., W.J. Wilson, and D. Mohr. 2010. Statistical methods. 3rd ed. Academic Press, London, UK.

Gallardo, R.K., K. Grant, D.J. Brown, J.R. McFerson, K.M. Lewis, T. Einhorn, and M.M. Sazo. 2019. Perceptions of precision agriculture technologies in the U.S. fresh apple industry. HortTechnology 29:151-162.

Gallardo, R.K., H. Li, V. McCracken, C. Yue, J. Luby, and J.R. McFerson. 2015. Market intermediaries' willingness to pay for apple, peach, cherry, and strawberry quality attributes. Agribusiness 31:259280.

Gallardo, R.K., J. Lusk, R. Holcomb, and P. Rayas-Duarte. 2009. Willingness to pay for attribute level and variability: The case of Mexican millers' demand for hard red winter wheat. J. Agr. Appl. Econ. 41:599611.

Gallardo, R.K., E.T. Stafne, L.W. DeVetter, Q. Zhang, C. Li, F. Takeda, J. Williamson, W.Q. Yang, W.O. Cline, R. Beaudry, and R. Allen. 2018. Blueberry producers' attitudes toward harvest mechanization for fresh market. HortTechnology 28:10-16.

Gallardo, R.K. and Q. Wang. 2013. Willingness to pay for pesticides' environmental features and social desirability bias: The case of apple and pear growers. J. Agr. Resour. Econ. 38:124-139.

Ghimire, S., D. Hayes, L.W. DeVetter, D.A. Inglis, J.S. Cowan, and C.A. Miles. 2018. Biodegradable plastic mulch and suitability for sustainable and organic agriculture. Washington State Univ. Ext. Publ. FS103E.

Goldberger, J.R., L.W. DeVetter, and K.E. Dentzman. 2019. Polyethylene and biodegradable plastic mulches for strawberry production in the United States: Experiences and opinions of growers in three regions. HortTechnology 29:619628.

Goldberger, J.R., R.E. Jones, C.A. Miles, R.W. Wallace, and D.A. Inglis. 2015. Barriers and bridges to the adoption of biodegradable plastic mulches for US 
specialty crop production. Renew. Agr. Food Syst. 30:143-153.

Greene, W.H. and D.A. Hensher. 2010. Modeling ordered choices: A primer. 1st ed. Cambridge University Press, New York, NY.

Hall, R.H., H.L. Collier, M.L. Thomas, and M.G. Hilgers. 2005. A student response system for increasing engagement, motivation, and learning in high enrollment lectures. Proceedings of the 1lth American Conference on Information Systems, Omaha, NE, 11-14 Aug. 2005.

Hoke, O., B. Campbell, M. Brand, and T. Hau. 2014. State and retail outlet impact on premiums for locally grown berries. 2014 Agricultural \& Applied Economics Association annual meeting, Minneapolis, MN, 27-29 July 2014.

International Organization for Standardization. 2012. Plastics: Determination of the ultimate aerobic biodegradability of plastic materials in soil by measuring the oxygen demand in a respirometer or the amount of carbon dioxide evolved (ISO Standard No. 17556). 30 Dec. 2019. <https://www.sis.se/api/document/ preview/915073>.

Jaeck, M. and R. Lifran. 2014. Farmers' preferences for production practices: A choice experiment study in the Rhone River delta. J. Agr. Econ. 65:112-130.

Kasirajan, S. and M. Ngouajio. 2012. Polyethylene and biodegradable mulches for agricultural applications: A review. Agron. Sustain. Dev. 32:501-529.

Krinsky, I. and A.L. Robb. 1986. On approximating the statistical properties of elasticities. Rev. Econ. Stat. 68:715-719.

Kuhfeld, W.F. 2005. Marketing research methods in SAS: Experimental design, choice, conjoint, and graphical techniques. SAS 9.2 ed. SAS Institute, Cary, NC.

Kyrikou, I. and D. Briassoulis. 2007. Biodegradation of agricultural plastic films: A critical review. J. Polym. Environ. 15:125-150.

Li, T. and J.J. McCluskey. 2017. Consumer preferences for second-generation bioethanol. Energy Econ. 61:1-7.

Li, Z., R.K. Gallardo, W. Hoashi-Erhardt, V.A. McCracken, C. Yue, and L.W. DeVetter. 2019. Supporting successful transition to the fresh market: Research and extension needs of Pacific Northwest strawberry growers. HortTechnology 29:649-658.

Loureiro, M.L., J.J. McCluskey, and R.C. Mittelhammer. 2001. Assessing consumer preferences for organic, eco-labeled, and regular apples. J. Agr. Resour. Econ 26:404-416.
Louviere, J.J., D.A. Hensher, and J.D. Swait. 2000. Stated choice methods: Analysis and applications. Cambridge University Press, New York, NY.

Lusk, J.L. and D. Hudson. 2004. Willingness-to-pay estimates and their relevance to agribusiness decision making. Rev. Agr. Econ. 26:152-169.

Lusk, J.L., M. Jamal, L. Kurlander, M. Roucan, and L. Taulman. 2005. A metaanalysis of genetically modified food valuation studies. J. Agr. Resour. Econ. 30:28-44.

Lusk, J.L. and F.B. Norwood. 2005. Effect of experimental design on choicebased conjoint valuation estimates. Amer. J. Agr. Econ. 87:771-785.

Lusk, J.L., J. Roosen, and J.A. Fox. 2003. Demand for beef from cattle administered growth hormones or fed genetically modified corn: A comparison of consumers in France, Germany, the United Kingdom, and United States. Amer. J. Agr. Econ. 85:16-29.

Lusk, J.L. and T.C. Schroeder. 2004. Are choice experiments incentive compatible? A test with quality differentiated beef steaks. Amer. J. Agr. Econ. 86:467-482.

McCarter, M.W. and A. Caza. 2009. Audience response systems as a data collection method in organizational research. J. Mgt. Organ. 15:122-131.

McFadden, D. and K. Train. 2000. Mixed MNL models for discrete response. J. Appl. Econ. 15:447-470.

Meloun, M. and J. Militky. 2011. Statistical data analysis: A practical guide. Woodhead Publishing, Sawston, UK.

Miles, C.A., R. Wallace, A. Wszelaki, J. Martin, J. Cowan, T. Walters, and D.A. Inglis. 2012. Deterioration of potentially biodegradable alternatives to black plastic mulch in three tomato production regions. HortScience 47:1270-1277.

Moreno, M.M. and A. Moreno. 2008. Effect of different biodegradable and polyethylene mulches on soil properties and production in a tomato crop. Scientia Hort. 116:256-263.

Nijs, V. 2019. Radiant: Business analytics using $\mathrm{R}$ and Shiny. $\mathrm{R}$ package version 1.3.1. 25 Feb. 2020. <https://github. com/radiant-rstats/radiant $>$.

Onken, K., J. Bernard, and J. Pesek. Jr. 2011. Comparing willingness to pay for organic, natural, locally grown, and state marketing program promoted foods in the mid-Atlantic region. Agr. Resour. Econ. Rev. 40:33-47.

Orme, B. 2010. Getting started with conjoint analysis: Strategies for product design and pricing research. 2nd ed. Research Publishers, Madison, WI.

Ouma, E., A. Abdulai, and A. Drucker. 2007. Measuring heterogeneous preferences for cattle traits amongst cattle keeping households in East Africa. Amer. J. Agr. Econ. 89:1005-1019.

Özkan, K., S. Ergin, Ş. Işık, and İ. Işıklı. 2015. A new classification scheme of plastic wastes based upon recycling labels. Waste Mgt. 35:29-35.

Pambo, K., D. Otieno, and J.J. Okello. 2015. Willingness-to-pay for sugar fortification in western Kenya. 16 Apr. 2020. $<$ https://ageconsearch.umn.edu / record/202970/files/AAEA $\% 20$ Paper\% 202015.pdf>.

Powe, B.D., R.C. Faulkenberry, L. Harmond, and D.L. Cooper. 2009. Evaluating the use of an audience response technology system to collect research data among African American elders. Ageing Intl. 34:60-66.

Revelt, D. and K. Train. 1998. Mixed logit with repeated choices: Households' choices of appliance efficiency level. Rev. Econ. Stat. 80:647-657.

Rillig, M.C., L. Ziersch, and S. Hempel. 2017. Microplastic transport in soil by earthworms. Scientific Rpt. 7:1362.

Scarascia-Mugnozza, G., C. Sica, and G. Russo. 2011. Plastic materials in European agriculture: Actual use and perspectives. J. Agr. Eng. 42:15-28.

Shi, L., L. House, and Z. Gao. 2011. Consumer WTP for blueberry attributes: A hierarchical Bayesian approach in the WTP space. 2011 Agricultural \& Applied Economics Association annual meeting, Pittsburgh, PA, 24-26 July 2011.

Sintim, H.Y. and M. Flury. 2017. Is biodegradable plastic mulch the solution to agriculture's plastic problem? Environ. Sci. Technol. 51:1068-1069.

Steinmetz, Z., C. Wollmann, M. Schaefer, C. Buchmann, J. David, J. Tröger, K. Muñoz, O. Frör, and G.E. Schaumann. 2016. Plastic mulching in agriculture: Trading short-term agronomic benefits for long-term soil degradation? Sci. Total Environ. 550:690-705.

Tonsor, G., N. Olynk, and C. Wolf. 2009. Consumer preferences for animal welfare attributes: The case of gestation crates. J. Agr. Appl. Econ. 41:714-730.

Touchaleaume, F., L. Martin-Closas, H. Angellier-Coussy, A. Chevillard, G. Cesar, N. Gontard, and E. Gastaldi. 2016. Performance and environmental impact of biodegradable polymers as agricultural mulching films. Chemosphere 144:433439. 
Train, K.E. 2003. Discrete choice methods with simulation. Cambridge University Press, New York, NY.

Train, K.E. 2009. Discrete choice methods with simulation, 2nd ed. Cambridge University Press, New York, NY.

Vox, G., R.V. Loisi, I. Blanco, G.S. Mugnozza, and E. Schettini. 2016. Mapping of agriculture plastic waste. Agr. Agr. Sci. Procedia 8:583-591.

Wongprawmas, R., G. Pappalardo, M. Canavari, and B. Pecorino. 2016. Willingness-to-pay for multiple units of eco- friendly wheat-derived products: Results from open-ended choice experiments. J. Food Prod. Mktg. 22:658-682.

Yue, C. and C. Tong. 2009. Organic or local? Investigating consumer preference for fresh produce using a choice experiment with real economic incentives. HortScience 44:366-371.

Yue, C., S. Zhao, K. Gallardo, V. McCracken, J. Luby, and J. McFerson. 2017. US growers' willingness to pay for improvement in rosaceous fruit traits. Agr. Resour. Econ. Rev. 46:103-122.
Zhang, H., R.K. Gallardo, J.J. McCluskey, and E. Kupferman. 2010. Consumers' willingness to pay for treatment induced quality attributes in Anjou pears. J. Agr. Resour. Econ. 35:105-117.

Zheng, X., C. Yue, R.K. Gallardo, V. McCracken, J. Luby, and J. McFerson. 2016. What attributes are consumers looking for in sweet cherries? Evidence from choice experiments. Agr. Resour. Econ. Rev. 45:124-142. 